DOI 10.37882/2500-3682.2021.01.10

\title{
ГЕНДЕРНАЯ ИДЕНТИФИКАЦИЯ МОЛОДЕЖИ В СОВРЕМЕННОМ СОЦИАЛЬНОМ ПРОСТРАНСТВЕ: ФИЛОСОФСКИЙ АСПЕКТ
}

\section{GENDER IDENTIFICATION OF YOUNG PEOPLE IN TODAY'S SOCIAL SPACE: THE PHILOSOPHICAL ASPECT FULL NAME \\ T. Nikolaeva}

Summary: The article examines the gender identification of young people in the modern social space within the framework of the philosophical aspect. The author notes that the most important stage in the development of modern society is the transformation of universal human values, sociocultural norms, traditions, including the institution of the family, which in turn leads to a discussion of gender identification of youth. The author also noted further directions of scientific research in this matter. The author emphasizes that the complex combination of social invariants, sociocultural norms and random events is a matrix due to which an individual is formed. All these value levels are strictly functional from a socio-philosophical point of view and are of particular interest to philosophical researchers. Thus, the author concludes that ideal utopian abstractions serve as a guide to final goals, specific values are the subject of real private values of youth.

Keywords: gender identification, youth, philosophy, gender, modern society.

\author{
Николаева Татьяна Анатольевна \\ к.ф.н., ФГБОУ ВО «Тихоокеанский государственный \\ университет», г. Хабаровск \\ 004012@pnu.edu.ru
}

Аннотация: В статье рассматривается гендерная идентификация молодежи в современном социальном пространстве в рамках философского аспекта. Автор отмечает, что важнейшим этапом развития современного общества является трансформация общечеловеческих ценностей, социокультурных норм, традиций, в том числе и института семьи, что в свою очередь обуславливает обсуждение гендерной идентификации молодежи. Автором также отмечены дальнейшие направления научных изысканий в данном вопросе. Автор подчеркивает, что сложное сочетание общественных инвариант, социокультурных норм и случайных событий представляют собой матрицу, благодаря которой формируется индивид. Все эти ценностные уровни строго функциональны с социально-философской точки зрения и представляют особый интерес для исследователей-философов. Таким образом автор делает вывод, что идеальные утопические абстракции служат ориентиром финальных целей, конкретные ценности - предметом реальных частных ценностей молодежи.

Ключевые слова: гендерная идентификация, молодежь, философия, гендер, современное общество.

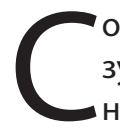
овременный этап развития общества характеризуется трансформацией общечеловеческих ценностей, социокультурных норм, традиций, в том числе и института семьи. Подобные преобразования в обществе влекут за собой и изменение результатов исследований в области семейной и возрастной психологии и философии. Так, с одной стороны молодые люди, получая родительские установки, построения семейных отношений, приносят их в свои собственные, культивируют и изменяют их собственным опытом, таким образом, следуют родительскому сценарию. С другой стороны, исследования показывают, что современные молодые люди имеют отличные от старшего поколения ценности и установки относительно брака и семьи и тем самым модернизируют современный институт семьи. Демографические показатели свидетельствуют о том, что на данном этапе значительно возросло количество разводов, и уменьшилась рождаемость, что оставляет свой след в изучении семейной психологии.

Таким образом, можно судить о неоднозначном положении современного института семьи и гендерной идентификации молодежи. Подобные исследования никогда не перестанут быть актуальными, так как общество меняется стремительно и научные сведения должны обновляться и дополняться. Так как институт семьи меняется, появляются все новые разновидности отношений между людьми. В нынешнем обществе, люди, например, с нетрадиционной сексуальной ориентацией вступают в гражданские браки и формируют семьи, как одни из представителей современной молодежи. Вместе с этим, особый интерес представляет внутренняя атмосфера брака, которая под собой содержит семейные установки, как основу для образования новых супружеских установок, составляющим один из основных объектов изучения в философском аспекте.

Установка - это первичное, целостное состояние, предшествующее сознательной психологической деятельности, и обуславливающее собой поведение человека [1]. Брачные установки имеют тенденцию предопределения возможной устойчивости брака. В этом случае достаточно значимым является процесс соотнесения установок человека с объективной реальностью отношений, от чего и зависит устойчивость дальнейшего брачного союза.

Аспекты, на которые выше было заострено внима- 
ние, демонстрирует актуальность исследования гендерной идентичности молодежи с позиции философского аспекта. На сегодняшний день проблемное поле, связанное с формированием и функционированием идентичности [7], в том числе этнической идентичности [2], и особенно гендерной идентичности и ее философской рефлексией является, без преувеличения, одним из наиболее востребованных, интересных и сложных [5].

Для нашего исследования, следует рассматривать гендер как часть особого социального языка, специфический текст, специфическую систему знаков имеет смысл анализировать и описывать в герменевтическом, феноменологическом и семиотическом ключе. Феноменологический инструментарий посредством исследования эволюции формы и содержания наиболее полно отражает постепенное переструктурирование гендера и гендерного сознания (поведения, гендерных практик) в процессе перехода от традиционного общества к современному (так может быть описан процесс постепенного выхода из жестких предписанных обществом гендерных ролей, переход к культуре самомоделирования и самопроектирования индивидуальной идентичности) [6].

В современном обществе совершенствование и трансформация внешнего облика приводит к повышению требований к индивидуальности, уникальности и заботе о себе [4, 7]. Уход за телом и внимание к элементам внешности отражается на содержании гендерной идентичности, определяя новые стандарты облика/требований мужчин и женщин. Более того, кардинальное изменение установок в отношении внешности касается не только женщин, но и мужчин.

Актуальность исследования определяется важностью построения телесного образа Я для гендерной самоидентификации в контексте жизненного самоопределения. Мы предполагаем, что динамическое социально - экономическое развитие общества приводит к усилению конкуренции и стиранию границ гендерной идентичности в телесном Я образе как у женщин, так и у мужчин [9]. Культ активности и здорового образа жизни создает тренд стремления к совершенству, размывая границы мужского-женского в социальных активностях, формах и линиях одежды, цветовых предпочтениях. Нацеленность на успех повышает значение принятия и понимания себя, ядром которого является образ тела и сформированная гендерная идентичность [3].

Телесный образ - представление о том, как мы выглядим, что думают о нас другие, строится на самоощущении тела и его отражении в сознании в виде слов, смыслов и образов Я.

Онтогенетическое формирование телесного Я происходит в процессе взаимодействия ребенка с окружа- ющей средой, и зависит не только от объективных параметров роста, веса, цвета кожи и разреза глаз, но и от тех субъективных оценок, которые им дают значимые другие. Наибольшую популярность данная тема связи телесного образа в зависимости от содержания. Внешний облик и телесный образ Я имеет ключевое значение в работах И. Кона, К. Роджерса, З. Фрейда, Е.Т. Соколова, К. Юнга, Р. Бернс, В.А. Петровского и др. Исследования показывают [1, 2, 5], что на формирование представления о себе оказывает влияние социальное окружение, семья, средства массовой информации. Особенно подвержены влиянию внешних факторов женщины, активно меняющие образ своего тела с помощью диет, спортивных тренировок, пластической хирургии, одежды и т.д.

Гендерная идентичность так же трансформируется под социально-психологическими и философскими факторами, с позиции общественных трендов. Особенно остро соответствие или не соответствие образа тела стандартам маскулинности-феминности переживается в молодости, поскольку влияет на выбор партнера, друзей, работы и стиля жизни. А проблемы в формирования образа тела приводят к проблемам в самоидентификации и самореализации [10].

Нами было проведено исследование, в рамках которого были выявлены философские аспекты гендерной идентичности молодежи. В исследовании приняли участие 80 человек - 40 женщин и 40 мужчин в возрасте от 20 до 30 лет. Уровень образования: 52 респондента имеют высшее образование, 28 - среднее специальное. Период после 20 лет является возрастом, когда телесный образ Я имеет устойчивую структуру. И именно в этом возрасте молодые люди особенно восприимчивы к изменениям в обществе и культуре, поскольку они активно строят личную жизнь, карьеру и отношения.

Анализ результатов гендерной идентичности испытуемых подтверждает тренд на размывание границ меду мужским и женским в современном обществе (таблица 1). Для большинства респондентов характерен андрогинный тип идентичности. Это можно объяснить тем, что андрогинность, умение проявлять в поведении как женские, так и мужские качества, позволяет молодым людям быть более адаптивными и гибкими в выборе вероятного типа поведения. Только пятеро мужчин по данным методики относятся к маскулинному типу личности, такое же число женщин с определением феминности, относятся к феминному типу личности. Также среди женщин две с маскулинным типом личности и трое мужчин относятся к феминному типу личности.

Необходимо отметить, что общее средний показатель маскулинности мужчин выше, чем у женщин. Что вполне объяснимо, поскольку обладание мужским телом позволяет более ярко проявлять маскулинные чер- 
ты в поведении. Так же, выраженность черт феминности у женщин ярче, чем у мужчин. При этом, значения средних значений маскулинности женщин гораздо выше, нежели показателя феминности у мужчин. Что еще раз подтверждает более высокую значимость маскулинности в современном обществе.

Таблица 1.

Гендерная идентичность молодежи,\%

\begin{tabular}{|l|c|c|c|c|}
\multicolumn{1}{|c|}{ Параметр } & $\begin{array}{c}\text { Мужчины } \\
\%\end{array}$ & $\begin{array}{c}\text { Среднее } \\
\text { значение }\end{array}$ & $\begin{array}{c}\text { Женщины } \\
\%\end{array}$ & $\begin{array}{c}\text { Среднее } \\
\text { значение }\end{array}$ \\
\hline Маскулинность & 12,5 & 5,425 & 5 & 3,175 \\
\hline Феминность & 7,5 & 2,6 & 12,5 & 4,5 \\
\hline Андрогинность & 80 & 0,92 & 82,5 & 0,81 \\
\hline
\end{tabular}

Результаты опросника MBSRQ, показывающего особенности эмоционально-оценочного отношения к собственному телу у молодых мужчин и женщин, представлены в таблице 2. Обработка полученных результатов позволяет утверждать, что молодые мужчины и женщины одинаково ориентированы на внешность. При этом, удовлетворенность параметрами тела не имеет существенных различий.

Таблица 2.

Особенности эмоционально-оценочного отношения к собственному телу и внешности

\begin{tabular}{|l|c|c|}
\multicolumn{1}{|c|}{ Субшкалы } & Мужчины & Женщины \\
\hline Оценка внешности & 1,9 & 1,68 \\
\hline Ориентация на внешность & 2,686 & 2,597 \\
\hline Удовлетворенность параметрами тела & 3,39 & 3,42 \\
\hline Озабоченность лишним весом & 1,787 & 2,85 \\
\hline Оценка собственного веса & 2,275 & 3,28 \\
\hline Самооценка & 2,68 & 3,66 \\
\hline Мотивация & 3 & 3,08 \\
\hline
\end{tabular}

Статистический анализ позволяет утверждать, что мужчины больше удовлетворены собственным весом, чем женщины. Это отражается и в наличии большей озабоченности лишним весом у женщин, чем у мужчин.

Сравнительный анализ оценочного представления своей внешности позволяет говорить о том, что молодые женщины больше удовлетворены своей внешностью, чем мужчины. Это можно объяснить тем, что женщины прилагают больше усилий для работы с телом и борьбы с лишним весом, поэтому замечают больше нюансов и даже небольшие изменения во внешности, которые явились следствием собственных усилий, замечаются и оцениваются положительно.

Статистическая обработка полученных данных позво- ляет говорить о том, что возраст не имеет корреляций ни с одним из исследуемых параметров. Значение максимальной для возраста отрицательной корреляции с образованием $(\neg 0,397)$ обнаруживает тенденцию снижения интереса к учебе с возрастом, что, однако, не является статистически достоверным. Кроме того, можно говорить о корреляции между показателями феминности у мужчин и удовлетворенностью параметрами тела $(0,487)$.

Значимые корреляционные связи для мужчин выявляются между маскулинностью и озабоченностью лишним весом (-0,501). А также ориентация на собственную внешность положительно коррелирует с самооценкой $(0,554)$ и мотивацией $(0,497)$. Самооценка положительно связана с мотивацией $(0,551)$ и общим отношением к собственному телу $(0,883)$.

Анализируя полученные результаты, можно утверждать, что параметр «веса» является наиболее значимым для формирования эмоционально-оценочного отношения к собственному телу. При этом, маскулинность отрицательно взаимосвязана с озабоченностью лишним весом $(-0,495)$. Можно говорить о том, что для маскулинных мужчин не характерен страх поправиться, лежащий в основе стремления контролировать вес и соблюдать сдержанность в еде.

У женщин выявлена значимая отрицательная корреляция между удовлетворенностью параметрами тела и озабоченностью лишним весом $(-0,572)$. Озабоченность лишним весом, в свою очередь, положительно коррелирует с отношением к собственному весу $(0,581)$. Озабоченность лишним весом не характерна для маскулинных женщин (-0.492)

Ориентация на внешность, которая характеризует степень вклада в свою внешность, положительно коррелирует с непосредственной заинтересованностью собственным телом $(0,493)$, мотивацией $(0,486)$ и самооценкой $(0,503)$. Можно предположить, что чем выше ориентация на внешность, тем больше самооценка человека в отношении своей внешности, и тем сильнее мотивация заниматься собственным телом. Основные выводы:

Современных молодых людей в возрасте от 20 до 30 лет отличает андрогинность, одинаковая представленность маскулинных и феминных качеств в структуре гендерной идентичности. При этом, женщины больше мотивированы на внешность и работу с собственным телом. Для мужчин ориентация на тело определяет самооценку и мотивацию. Отношение к образу собственного тела зависит от маскулинности - феминности в структуре гендерной идентичности. Маскулинность как у мужчин, так и у женщин, отрицательно коррелирует с отношением к лишнему весу, феминность положительно коррелирует с ним. 
Таким образом, сложное сочетание общественных инвариант, социокультурных норм, и даже случайных событий становится матрицей, внутри которой формируется индивид (и происходит репрезентация, его гендерной идентичности, в зависимости от биологического пола, а иногда, в последнее время, даже вопреки ему). На уровне языка как знаково-коммуникативной системы эти гендерные практики всегда имеют свою проекцию, отражение, что может быть релевантно описано в методологическом формате герменевтики. Аксиологический подход также может быть признан как релевантный и дополняющий герменевтический. При этом ценности могут быть представлены как реально действующие регуляторы, необходимые для нормативной определенности гендерной иерархии общества, в ценностных системах происходит встречное движение: от абстрактных к конкретным формам и обратное - к абстракциям и идеалам. Все эти ценностные уровни строго функциональны с социально-философской точки зрения. Идеальные утопические абстракции служат ориентиром финальных целей, конкретные ценности - предметом реальных частных ценностей.

\section{ЛИТЕРАТУРА}

1. Авдонина Н.А. Образ тела как компонент самосознания в юношеском возрасте// Вестник ассоциации вузов туризма и сервиса. Том 2. № 2, 2016. С. 77-85.

2. Коломийченко Е.В. Самоотношение и гендерная идентичность как факторы формирования образа телесности у современной молодежи. Теория и практика общественного развития, 2015. № 16. С. 268-271.

3. Номеровская А.Д. Понятие нормативности в современных теориях гендерной идентичности/ Парадигма: философско-культурологический альманах, 2017. № 26. С. 49-66.

4. Каминская, Н.А. Исследования образа физического «Я» различных психологических школах / Н.А. Каминская, А.М. Айламазян // Национальный психологический журнал. - 2015. - № 3 (19). - С. 45-55.

5. Бахман-Медик Д. Культурные повороты. Новые ориентиры в науках о культуре / пер с нем. М.: Новое литературное обозрение. 2017. 504 с.

6. Воронина 0.А. Основные идеи и концепты феминистской социальной эпистемологии // Вестник Пермского университета. Философия. Психология. Социология. 2017. Вып. 2. С. 141-151.

7. Номеровская А.Д. Исследование гендерной идентичности в философско-антропологической перспективе: дис. .... канд. филос. наук. СПб., 2015. 168 с.

8. Техника «косого взгляда». Критика гетеронормативного порядка / под ред. И. Градинари. М.: Изд-во Ин-та Гайдара, 2015. 352 с.

9. Труфанова Е.О. Субъект и познание в мире социальных конструкций. М.: Канон+: РООИ «Реабилитация», 2018.320 с.

10. Фетисова Е.Н. Несимметричные гендерные интеракции в пространстве образования // Образовательная система: новации в сфере современного научного знания: Материалы Международных научно-практических мероприятий 0бщества Науки и творчества (г. Казань) за февраль 2019 года / Под общ. ред. С.В. Кузьмина. - Казань, 2019.

( ) Николаева Татьяна Анатольевна (004012@pnu.edu.ru).

Журнал «Современная наука: актуальные проблемы теории и практики» 